\section{HAND HYGIENE COMPLIANCE RATES AND BARRIERS TO COMPLIANCE IN PEDIATRIC} UNITS IN GREECE

Chorianopoulou E. ${ }^{1}$, Baka M. ${ }^{2}$, Charalampopoulos D. ${ }^{3}$,

Christopoulou G. ${ }^{4}$, Dimitriou G. ${ }^{5}$, Drougia A. ${ }^{6}$, Gaitana A. ${ }^{7}$,

Karavana G. ${ }^{8}$, Koropouli M. ${ }^{9}$, Kouni S. ${ }^{1}$, Kourkouni E. ${ }^{1}$, Lourida A. ${ }^{10}$ Papadatos I. ${ }^{11}$, Roilides E. ${ }^{12}$, Syrogianni A. ${ }^{3}$, Tsouvala E. ${ }^{13}$, Zaoutis TE. ${ }^{1}$

\section{Background:}

Hand hygiene $(\mathrm{HH})$ is the most important measure to prevent healthcare associated infections and avoid transmission of pathogens. The aim of the study was to determine $\mathrm{HH}$ compliance rates in pediatric units and identify barriers for compliance among health care workers (HCWs).

\section{Methods:}

An observational study for $\mathrm{HH}$ rates was carried in 24 pediatric units (15 NICUs, 4 PICUs and 5 oncology units) from June 2016 to February 2017 in 14 hospitals in Greece.

Observations were collected during all shifts in wards by trained on $\mathrm{HH}$ methods observers, using a data collection form based upon tools from WHO.

At the end of this period, a questionnaire was provided to $\mathrm{HCWs}$ to detect the possible barriers for $\mathrm{HH}$ compliance.

Figure 1: HH compliance rate(\%) stratified by type of unit for the period Jun16-Feb17

$$
100
$$

$$
80
$$

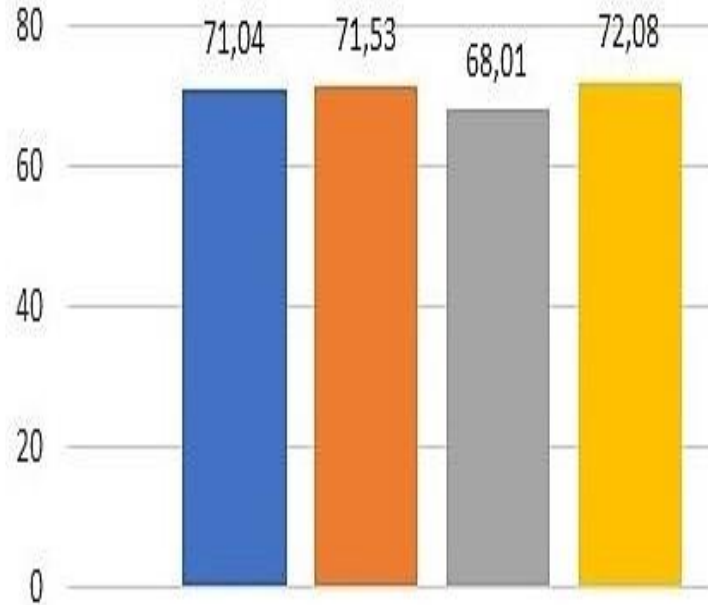

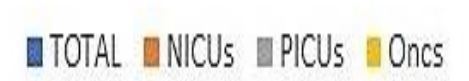

\section{Results:}

A total of $6472 \mathrm{HH}$ opportunities were observed. The total $\mathrm{HH}$ compliance rate was $71.04 \%$ while for NICUS, PICUS, ONCs was $71.53 \%, 68.01 \%$, and $72.08 \%$, respectively (Figure 1).The $\mathrm{HH}$ compliance rate ranged from $47.9 \%$ to $88.8 \%$ in NICUs, $67.9 \%-82.4 \%$ in PICUs and $36.4 \%$ $86.9 \%$ in ONCs. The total appropriate $\mathrm{HH}$ rate was $52.15 \%$. Stratified analysis by role was also conducted. Compliance rates for doctors and nurses in NICUs was $71.2 \%$ and $75.4 \%$ respectively, $66.1 \%$ and $79.9 \%$ in PICUs respectively, $89.3 \%$ and $85.5 \%$ in ONCs respectively.
Figure 2 : HH compliance rate by role $\%$

$$
\begin{array}{r}
100 \\
90 \\
80 \\
70 \\
60 \\
50 \\
40 \\
30 \\
20 \\
10 \\
0
\end{array}
$$

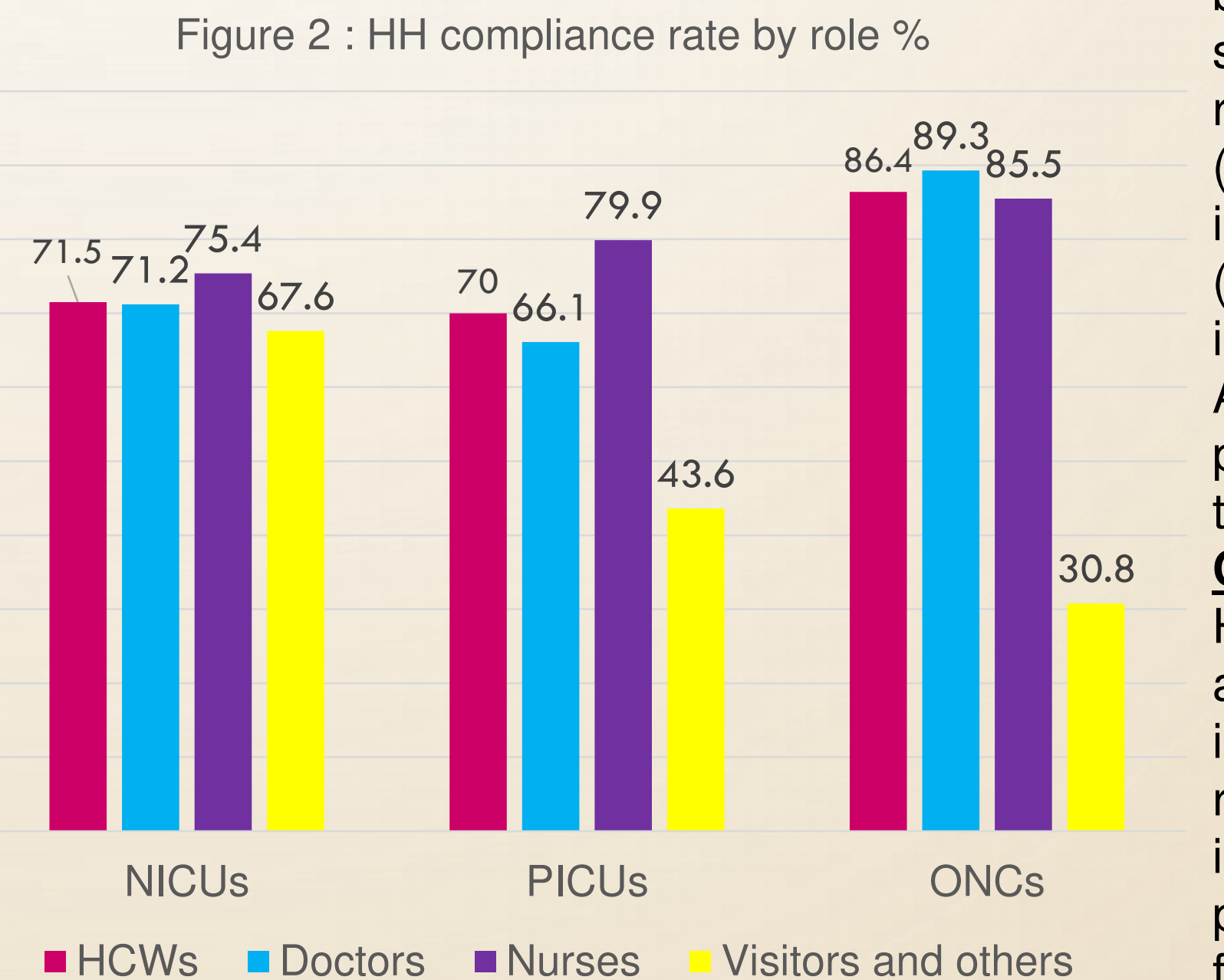
declare their beliefs about the barriers for $\mathrm{HH}$ (response rate: $48.3 \%$ ). As main barriers were detected: the emergency situation $(73.5 \%)$, distraction from many responsibilities during the patient care $(47.0 \%)$, great workload $(34.3 \%)$, and skin irritation from hand cleaning product $(24.3 \%)$. Figure 3 presents the most important possible barriers in questionnaire. Almost half of the respondents did not participate in $\mathrm{HH}$ educational activity during the past year.

\section{Conclusion}

$\mathrm{HH}$ compliance rates among pediatric units are high but still have the potential of improvement. Some of the reasons that reported by HCWs beliefs can be used to increase $\mathrm{HH}$ rates during intervention period. Defining the specific causes of $\mathrm{HH}$ failure requires more specific interventions targeted to its most important causes. 